\title{
Bone Marrow Infiltration by Nonhematopoetic Small Round Cell Tumors: A Clinicopathological Study from a Tertiary Care Centre in South India
}

\begin{abstract}
Objectives: The objective of this study to comprehensively analyze bone marrow (BM) infiltration by nonhematological round cell tumors. Materials and Methods: A total of 206 diagnosed cases of small round blue cell tumors (excluding lymphomas) during a period of $2 \frac{1}{2}$ years, referred for BM examination were included in the study. Clinical details were obtained from medical records. $\mathrm{BM}$ aspiration (BMA) and $\mathrm{BM}$ biopsies (BMBx) were performed under local anesthesia for staging workup. BMBx were studied for cellularity, presence of infiltration by round cells (nonhematopoietic), histologic patterns (island/nests and diffuse sheets), fibrosis, necrosis and other secondary changes. Immunohistochemistry panel was used depending on the morphology. Results: The cases included age range from 45 days to 25 years with a median age of 12 years. There was a male predominance with male:female 1.5:1. Among these, $37 / 206$ cases (17.9\%) were positive for BM involvement (BMI) on BMBx. Of these, 24 cases were neuroblastoma (64.8\%), 9 cases Ewing's sarcoma/primitive neuroectodermal tumor (24.3\%), and 4 Rhabdomyosarcoma (10.8). BMBx was done in all the 206 cases. Among these, 37/206 cases were positive for BMI on BMBx while 35/206 cases were positive on BM imprints and 33/206 cases were positive on BMA. Conclusion: Detection of metastasis in the BM has both therapeutic and prognostic significance. BMBx are complementary in the diagnosis of small round cell tumor.
\end{abstract}

Keywords: Bone marrow biopsy, Ewings/primitive neuroectodermal tumor, marrow infiltration, neuroblastoma, nonhematopoetic small round cell tumors

\section{Introduction}

Malignant small round cell tumors is a term used for tumors composed of malignant round cells that are slightly larger or double the size of red blood cells (RBCs) in air-dried smears and patternless sheets of small round cells with dense cellularity and high $\mathrm{N}: \mathrm{C}$ ratio on hematoxylin and eosin $(\mathrm{H}$ and $\mathrm{E})$. Bone marrow $(\mathrm{BM})$ is commonly infiltrated by hematopoietic tumors. Metastasis of nonhematopoietic tumor cells to BM was first reported in 1834; however, a series of such cases was not published until 1936. ${ }^{[1]}$ In 1958, McFarland and Dameshek ${ }^{[2]}$ described a simplified technique for BM biopsy and demonstrated that one could discover unsuspected malignant disease and in many cases confirm the finding obtained by aspiration. The extension of a cancer is a major prognostic factor (Stage IV disease) which determines the therapeutic strategy.

\footnotetext{
This is an open access journal, and articles are distributed under the terms of the Creative Commons AttributionNonCommercial-ShareAlike 4.0 License, which allows others to remix, tweak, and build upon the work non-commercially, as long as appropriate credit is given and the new creations are licensed under the identical terms.
}

For reprints contact: reprints@medknow.com
Small round cell tumors present more commonly during childhood and adolescent. Nonhematopoietic small round cell tumors include: Ewing sarcoma/primitive neuroectodermal tumor, retinoblastoma, rhabdomyosarcoma, nephroblastoma, mesenchymal chondrosarcoma, small cell osteosarcoma, poorly differentiated chordoma, melanotic neuroectodermal tumor, desmoplastic small round cell tumor, and germ cell tumors. ${ }^{[3]}$ The recognition of metastasis in random biopsies presents challenges to pathologists when diagnosing the primary focus and needs an extensive workup. ${ }^{[4]}$

The recent improvements in immunohistochemistry and molecular biology methods enable to detect tumor cells in various sites such as lymph nodes, BM, and blood with a considerably increased sensitivity as compared to conventional approaches. ${ }^{[5]}$ This study was undertaken to comprehensively analyze BM metastasis of nonhematological round cell

How to cite this article: Bhopal T, Hussain A, Mallikarjun S, Lakshmi S, Sinha S. Bone marrow infiltration by nonhematopoetic small round cell tumors: A clinicopathological study from a tertiary care centre in South India. Indian J Med Paediatr Oncol 2019;40:S1-5.

\section{Triveni Bhopal, Abid Hussain, Sai Mallikarjun, Sree Lakshmi, Sudha Sinha ${ }^{1}$}

Departments of Pathology and ${ }^{1}$ Medical Oncology, MNJ Institute of Oncology and Regional Cancer Centre, Hyderabad, Telangana, India

Address for correspondence: Dr. Abid Hussain, Department of Pathology, MNJ Institute of Oncology and Regional Cancer Centre, Beside Niloufer Hospital, Niloufer Road, Red Hills, Bazar Ghat, Hyderabad - 500004 , Telangana, India.

E-mail: hussain.abid111@gmail. com

Access this article online

Website: www.ijmpo.org

DOI: 10.4103/ijmpo.ijmpo_218_17 Quick Response Code:

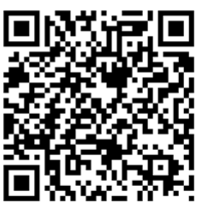


tumors diagnosed at a single tertiary care center in South India over the $2 \frac{1}{2}$ years.

\section{Materials and Methods}

This retrospective study was conducted from January 2014 to June 2016. A total of 206 diagnosed cases of small round blue cell tumors (excluding lymphomas), referred for BM examination were included in the study. Age and sex distribution, clinical findings and investigations (including ultrasound, X-rays, computed tomography scan, magnetic resonance imaging, and biopsy findings of primary tumor) of all patients were noted. An ethylenediaminetetraacetic acid-blood sample was obtained for complete blood picture and peripheral blood film examination. Peripheral blood smears were stained by Leishmann stain. BM aspiration (BMA) was performed by $16 \mathrm{G}$ lumbar puncture needle and subjected to staining by Giemsa stain. BM biopsies (BMBx) were obtained using the conventional technique with a Jamshidi needle from the posterior superior iliac spine under local anesthesia. The biopsies were of adequate $(1.5-2 \mathrm{~cm})$ length and fixed in $10 \%$ formalin solution and decalcified using $10 \%$ formal - formic acid for $4-6 \mathrm{~h}$ followed by routine processing and paraffin embedding. ${ }^{[5]}$ Serial sections of 4-6 $\mu \mathrm{m}$ thickness were cut and stained by $\mathrm{H}$ and $\mathrm{E}$ and supplemented with immune stains where ever required. Hematological parameters including hemoglobin, total leukocyte count and platelet count, and peripheral blood film examination with RBC morphology or presence of any atypical cells on peripheral blood were noted. A detailed examination of BM smears was done particularly for presence of atypical cells. BMBx sections with at least five well preserved marrow spaces were studied for cellularity, normal hematological elements, presence of infiltration by round cells (nonhematopoietic), histologic pattern and morphology of infiltration (island/nests, diffuse sheets), reticulin fibrosis, necrosis, and other secondary changes. Immunohistochemistry (IHC) panel included CD56, CD99, synaptophysin, chromogranin, S100, desmin, myogenin, and vimentin depending on the morphology.

\section{Results}

Demographic and clinical aspects

BMA $(n=206)$, imprints BMA, and BMBx $(n=206)$ were studied for involvement by round cell tumors from January 2014 to June 2016. The cases included age range from 45 days to 25 years with a median age of 12 years. There was a male predominance with male: female 1.5:1.

\section{Bone marrow aspirate and biopsy findings}

A total number of BMA were 4137 of which 206 (5\%) had an established clinical diagnosis of round cell tumor. Among these, 33/206 (16.01\%) cases were positive for BM involvement (BMI). Erythroid hyperplasia was seen in $10 / 206(4.8 \%)$, reactive marrow in $10 / 206(4.8 \%)$ and marrow within normal limits in 186/206 (90.2\%). Leukoerythroblastic picture was seen in 9/206 (4.3\%) cases on peripheral blood examination.

In 33 cases, BMA showed involvement by round cell tumor, in two cases, tumor was picked up in the imprint smear and biopsy, while in two other cases, both aspirate and imprint smears were negative but was positive on biopsy. Of the 33 positive cases in BMA, 22 cases were neuroblastoma $(66.6 \%), 8$ cases Ewing's sarcoma $(24.2 \%)$, and 3 cases of rhabdomyosarcoma (9.1\%). Distribution of the cases with BMI and IHC is shown in Table 1.

\section{Bone marrow biopsy findings}

A total number of BMBx were 206 which had an established clinical diagnosis of round cell tumor. Among these, 37/206 (17.9\%) cases were positive for BMI. Stromal changes such as fibrosis were seen in nine cases. Six out of 9 cases were positive for BMI by round cell tumors. Necrosis was seen in two cases of Ewings sarcoma. The remaining cases showed normal marrow.

\section{Immunohistochemistry}

IHC was done on BMBx using the panel comprising of leukocyte common antigen, CD99, CD56, desmin, vimentin, synaptophysin, and S100 depending on the

Table 1: Distribution of cases with bone marrow infiltration on bone marrow aspiration, bone marrow imprint, bone marrow biopsy

\begin{tabular}{|c|c|c|c|c|}
\hline Type of SRCT & $\begin{array}{l}\text { Clinical Dx of } \\
\text { SRCT }(n=206) \\
\end{array}$ & $\begin{array}{c}\text { Number of cases with BMA } \\
\text { involvement }(n=33 / 206)\end{array}$ & $\begin{array}{l}\text { Number of cases with BM } \\
\text { imprint involvememt }(n=35 / 206)\end{array}$ & $\begin{array}{l}\text { Number of cases with BMBx } \\
\text { involvement }(n=37 / 206)\end{array}$ \\
\hline Neuroblastoma & 84 & 22 & 22 & $\begin{array}{l}24 \text { (including } 2 \text { cases that } \\
\text { were -ve on BMA and BMI) }\end{array}$ \\
\hline Ewings sarcoma/PNET & 80 & 8 & $\begin{array}{l}9 \text { (including } 1 \text { case that was }-\mathrm{ve} \\
\text { on BMA) }\end{array}$ & $\begin{array}{l}9 \text { (including } 1 \text { case that was } \\
- \text { ve on BMA) }\end{array}$ \\
\hline Rhabdomyosarcoma & 35 & 3 & $\begin{array}{l}4 \text { (including } 1 \text { case that was }-\mathrm{ve} \\
\text { on BMA) }\end{array}$ & $\begin{array}{l}4 \text { (including } 1 \text { case that was } \\
\text {-ve on BMA) }\end{array}$ \\
\hline Medulloblastoma & 4 & - & - & - \\
\hline Wilms tumor & 2 & - & - & - \\
\hline Hepatoblastoma & 1 & - & - & - \\
\hline
\end{tabular}

BM - Bone marrow; BMBx - BM biopsy; SRCT - Small round cell tumors; BMA - BM aspiration; PNET - Primitive neuroectodermal tumor; $\mathrm{BMI}-\mathrm{BM}$ involvement 


\begin{tabular}{|c|c|c|c|c|}
\hline Features & $\begin{array}{c}\text { Present study } \\
(n=206), n(\%)\end{array}$ & $\begin{array}{l}\text { Naghmi Asif et al. } \\
(n=82), n(\%)\end{array}$ & $\begin{array}{l}\text { Mishra et al. } \\
(n=50), n(\%)\end{array}$ & $\begin{array}{c}\text { Rafiq et al. } \\
(n=14), n(\%)\end{array}$ \\
\hline Age range & 1.5 months to 25 years & 6 months to 22 years & $1-65$ years & $1-25$ years \\
\hline $\begin{array}{l}\text { BMA involvement by small round cell } \\
\text { tumor }\end{array}$ & $33 / 206(16.01)$ & $16 / 82(19.5)$ & $9 / 50(18)$ & $7 / 14(50)$ \\
\hline $\begin{array}{l}\text { BMBx involvement by small round cell } \\
\text { tumor }\end{array}$ & $37 / 206(18)$ & $14(17)$ & $9 / 50(18)$ & $7 / 14(50)$ \\
\hline Neuroblastoma & $24 / 84(28.5)$ & $2 / 5(40)$ & $2 / 5(40)$ & $3 / 3(100)$ \\
\hline Ewing's sarcoma & $9 / 80(11.2)$ & $3 / 6(50)$ & $6 / 28(21)$ & $1 / 2(50)$ \\
\hline Rhabdomyosarcoma & $3 / 35(8)$ & $3 / 8(37)$ & $0 / 9(0)$ & $2 / 3(66)$ \\
\hline
\end{tabular}

$\mathrm{BM}$ - Bone marrow; BMBx - BM biopsy; BMA - BM aspiration

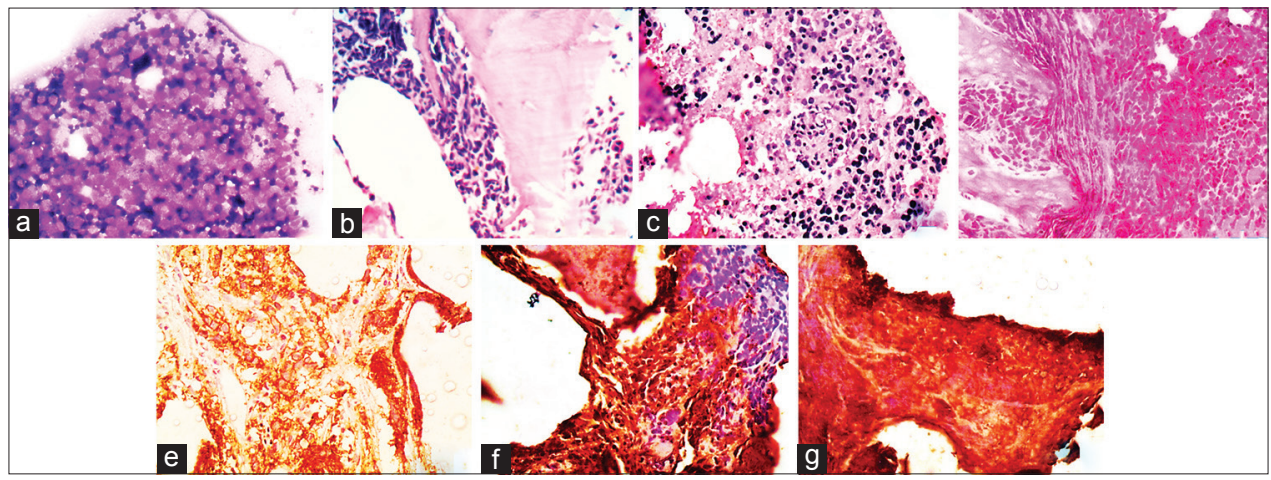

Figure 1: A case of neuroblastoma with bone marrow infiltration (a) trephine imprint showing atypical round cells $(\times 400)(b-d)$ Bone marrow biopsy displaying paratrabecular, interstitial and diffuse pattern of infiltration by round cells, respectively $(\times 100)(e)$ immunohistochemistry with CD56 showing cytoplasmic and membranous positivity $(\times 100)$, $(f$ and $g)$ the round cells showing positivity for vimentin and neuron-specific enolase, respectively $(\times 100)$

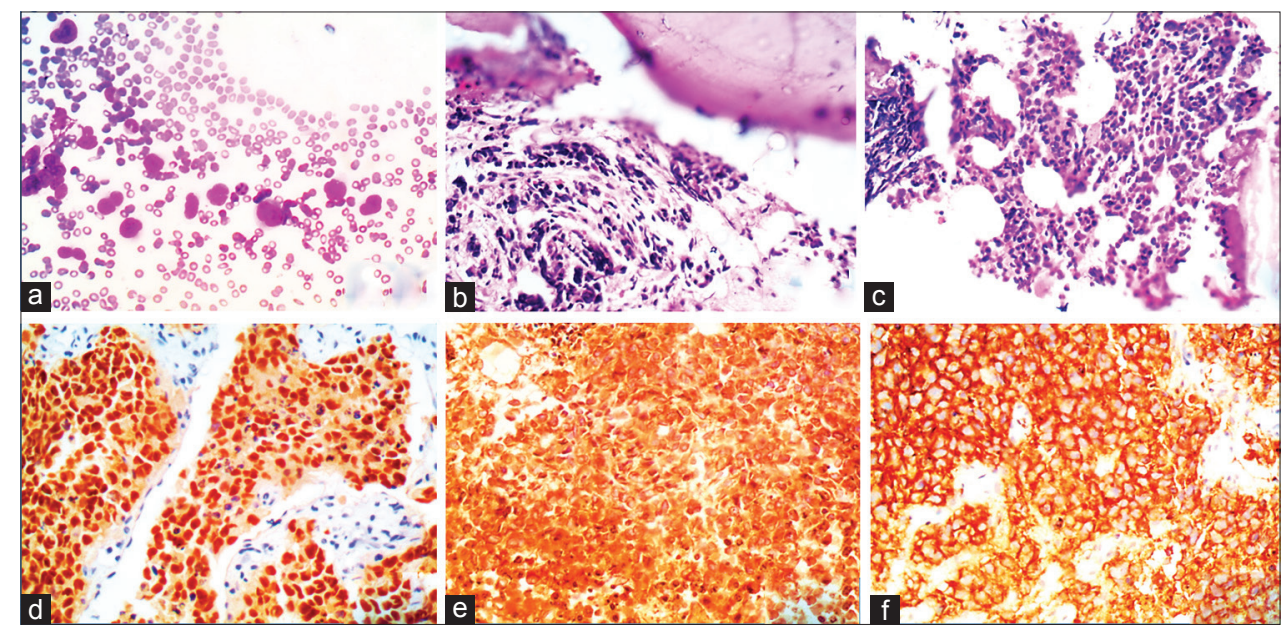

Figure 2: A case of rhabdomyosarcoma with bone marrow infiltration (a) bone marrow aspiration smears showing singly scattered large atypical round cells with scant cytoplasm and large bizarre nuclei with dispersed chromatin $(\times 400)(b$ and $c)$ bone marrow biopsy displaying paratrabecular and interstitial pattern of infiltration by round cells, respectively $(\times 400$ and $\times 100)$. (d-f) immunohistochemistry with myogenin, vimentin, and CD56 showing positivity $(\times 100)$

morphology. IHC was done in cases with high suspicion on histomorphology and all the cases of BMBx (37 cases) with established diagnosis of primary round cell tumor.

\section{Discussion}

\section{Peripheral blood}

Of the 37 positive cases, $6(16.2 \%)$ had leukoerythroblastic picture with immature granulocytes and nucleated red cells in the peripheral smear. Similarly, Contreras et al. ${ }^{[6]}$ found leukoerythroblastic picture in $22 \%$ of their cases and Leland and MacPherson ${ }^{[7]}$ in $33 \%$ of their cases. In our study, nucleated red cell and immature granulocytes were seen when the hemoglobin was reduced below $7.0 \% \mathrm{gm}$. The presence of leukoerythoblasticanemia correlates with the degree of reactive BM fibrosis than with the extent of malignant infiltration. ${ }^{[8]}$ In our study, all the six cases showed marrow fibrosis. 


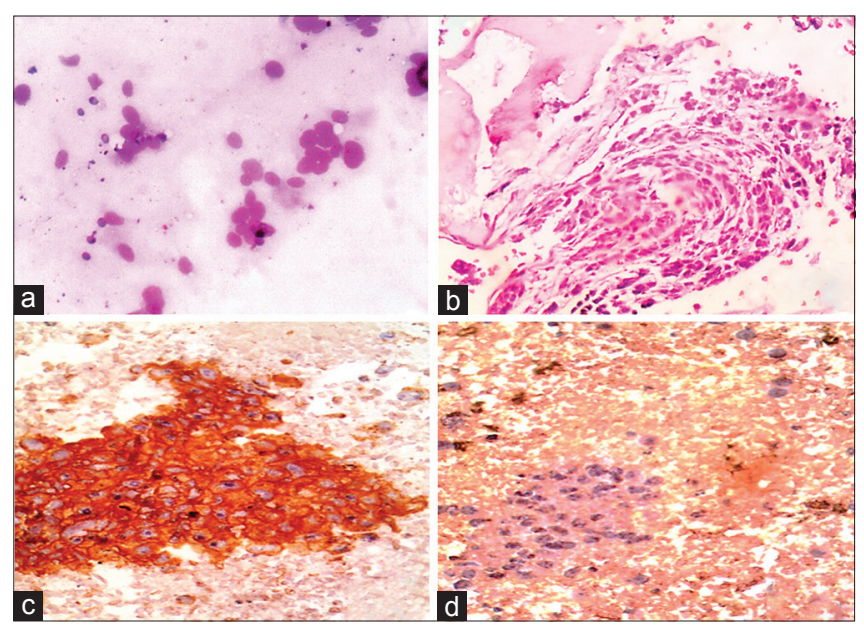

Figure 3: A case of Ewings/primitive neuroectodermal tumor with bone marrow infiltration (a) bone marrow aspiration smears showing rosettes and singly scattered round cells with scant cytoplasm and round nuclei with dispersed chromatin $(\times 400)(b)$ bone marrow biopsy displaying paratrabecular pattern of infiltration by round cells $(\times 400)$ (c and $d$ ) immunohistochemistry with CD99 showing membrane and cytoplasmic positivity and negativity with CD56 $(\times 400)$

\section{Bone marrow}

BM study is essential not only for hematological malignancies but also is equally important for nonhematological small round cell tumors. Bone is a common site for metastasis for these tumors and the presence of isolated tumor cells in the BM at the time of diagnosis indicates an increased risk for subsequent development of distant metastasis. In our study, we found BM infiltration by round cell tumors as 37/206 (17.9\%) on BMA. Similarly, Asif et al. ${ }^{[3]}$ from Pakistan found BMI in $19.5 \%$ cases $(n=82)$. Mishra et al. ${ }^{[9]}$ found $10 \%(n=50)$. This is in contrast with a study done by Rafiq et $a l .^{[10]}$ at King Edward Medical University which showed infiltration in 50\% cases; however, this may not be a true representation of disease as their cases were only 14. In our study, BM infiltration was seen maximum by neuroblastoma $24 / 84(28.5 \%)$ [Figure 1], followed by [Figure 2] Ewings sarcoma 9/80 (11.2\%) [Figure 3] and then RMS $3 / 35(8.5 \%)$ as seen in other studies, such as Naghmietal. Similarly in a study done by Kumar et al., ${ }^{[11]}$ BMI was highest in neuroblastoma 9/14 (64\%), Ewing's sarcoma $14 / 47$ (29.7\%), retinoblastoma $3 / 7(42.8 \%)$, and in rhabdomyosarcoma 5/20 (20\%). The lower number of Ewing's sarcoma in our studies, as compared to the other study mentioned, is probably due to the fact that not all the cases of Ewing's sarcoma are referred to us for BM biopsy. In a study by Mishra et al., the most common tumor in children that metastasized to marrow was neuroblastoma and Ewing's sarcoma each being 40\%.

In our study, 33 cases showed involvement by round cell tumor on BMA, in 2 cases tumor was picked up in the imprint smear and biopsy, while in 2 other cases both aspirate and imprint smears were negative; however, biopsy was positive, with an overall positive cases being 37 of the total 206 cases of small round cell tumors.

There have been several previous studies showing superiority of the BMBx over aspirate smears in diagnosis of metastatic tumor ${ }^{[12,13]}$ as deposits in the marrow are focal and may often elicit a fibrotic response, and therefore, aspirates may be negative. Multiple sections of the biopsy enable a much larger volume of the marrow to be examined and allow infiltration to be recognized. ${ }^{[14]}$ Singh et $a l .^{[12]}$ reported that $\mathrm{BMBx}$ was superior to aspiration (97\% vs. $72 \%$ ), Mishra et al. showed (100\% vs. $91.3 \%)$ similar findings were observed in our study where biopsy versus aspiration positivity is (100\% vs. $89.1 \%)$ [Table 2]. However, a study conducted by Sharma et al. ${ }^{[15]}$ showed an occasional case where metastasis was detected only in aspiration. Bearden et al. ${ }^{[16]}$ reported that BMAs and BMBx were complementary in diagnosis of various solid tumors.

Immunohistochemistry was used as an adjunct to the morphological findings in the marrow in elucidating the primary site, especially in clinically unsuspected cases. Depending on the morphology of the tumor appropriate immunohistochemistry panel was used to narrow down the differentials.

The presence of marrow infiltration is the most adverse prognostic factor and is associated with the disease progression and a poor clinical outcome. As these patients are at high risk of progression, they may benefit from intensification of the therapy. ${ }^{[17]}$ It is therefore stressed to routinely consider BM examination (aspiration and biopsy) for proper staging and management of these patients. BM metastasis, however, may not be evident only on routine microscopic examination and thus looking at different studies ${ }^{[18]}$ our recommendation is to move on to immunohistochemical staining and molecular studies of BM samples for the detection of minimal disseminated disease at the time of diagnosis.

\section{Conclusion}

Detection of metastasis in the BM has both therapeutic and prognostic significance. Clinical history, radiological findings, morphology, and immunohistochemistry with a panel of antibodies are useful to arrive at a definitive diagnosis. BMAs and $\mathrm{BMBx}$ are complementary in the diagnosis of small round cell tumors.

\section{Acknowledgment}

The authors would like to acknowledge the support from technical staff from the Department of Histopathology.

Financial support and sponsorship

Nil.

\section{Conflicts of interest}

There are no conflicts of interest. 


\section{References}

1. Samson M. Fait remarkable de diathesecancereuse. Gaz Med Paris 1834;2:140.

2. Rohr K, Hegglin R. Tumorzellen in sternapunktat. Dtsch Arch Klin Med 1936;179:61-79.

3. Asif N, Hassan K, Yasmeen N. Bone marrow infiltration in small blue cell tumours. J Islamabad Med Dent Coll (JIMDC) 2013;2:3-8.

4. Papac RJ. Bone marrow metastases. A review. Cancer 1994;74:2403-13.

5. Schleiermacher G, Delattre O. Detection of micrometastases and circulating tumour cells using molecular biology technics in solid tumours. Bull Cancer 2001;88:561-70.

6. Contreras E, Ellis LD, Lee RE. Value of the bone marrow biopsy in the diagnosis of metastatic carcinoma. Cancer 1972;29:778-83.

7. Leland $\mathrm{J}$, MacPherson B. Hematologic findings in cases of mammary cancer metastatic to bone marrow. Am J Clin Pathol 1979;71:31-5.

8. Rubins JM. The role of myelofibrosis in malignant leukoerythroblastosis. Cancer 1983;51:308-11.

9. Mishra P, Das S, Kar R, Jacob SE, Basu D. Non-haematopoietic malignancies metastasing to the bone marrow: A 5 year record-based descriptive study from a tertiary care centre in South India. Indian J Cancer 2014;51:30-4.
10. Rafiq H, Khurshid R, Zia R, Hayee A. Frequency of bone invasion and metastasis in round cell tumors of pediatric age groups. Biomedica 2007;23:8-11.

11. Kumar L, Majhi U, Shanta V. Frequency of bone marrow involvement in non-haematological malignancies. J Assoc Physicians India 1990;38:553-5.

12. Singh G, Krause JR, Breitfeld V. Bone marrow examination: For metastatic tumor: Aspirate and biopsy. Cancer 1977;40:2317-21.

13. Ingle JN, Tormey DC, Tan HK. The bone marrow examination in breast cancer: Diagnostic considerations and clinical usefulness. Cancer 1978;41:670-4.

14. Basu D, Singh T, Shinghal RN. Micrometastasis in bone marrow in breast cancer. Indian J Pathol Microbiol 1994;37:159-64.

15. Sharma $\mathrm{S}$, Murari $\mathrm{M}$. Bone marrow involvement by metastatic solid tumors. Indian J Pathol Microbiol 2003;46:382-4.

16. Bearden JD, Ratkin GA, Coltman CA. Comparison of the diagnostic value of bone marrow biopsy and bone marrow aspiration in neoplastic disease. J Clin Pathol 1974;27:738-40.

17. Imran R, Aejaz S, Banday MA, Ahmad SN. Extrarenal Wilms' tumour with bone marrow involvement: An index case report. Chin Ger J Clin Oncol 2010;9:295-7.

18. Krsková L, Mrhalová M, Hilská I, Sumerauer D, Drahokoupilová E, Múdry $\mathrm{P}$, et al. Detection and clinical significance of bone marrow involvement in patients with rhabdomyosarcoma. Virchows Arch 2010;456:463-72. 